NOTA CIENTÍFICA

\title{
AVALIAÇÃO DA VIABILIDADE DE SEMENTES DE CORAÇÃO-DE-NEGRO (Poecilanthe parviflora BENTH. - FABACEAE-FABOIDEAE) PELO TESTE DE TETRAZÓLIO ${ }^{1}$
}

\author{
TAIS L. F. PINTO², PEDRO H. S. BRANCALION³ , ANA D. L. C. NOVEMBRE ${ }^{4}$, SILVIO M. CICERO ${ }^{5}$
}

\begin{abstract}
RESUMO - A crescente demanda por sementes de espécies arbóreas brasileiras tem sido acompanhada pelo aumento da necessidade em se desenvolver métodos para a avaliação da viabilidade das sementes, principalmente por meio de testes rápidos, como o de tetrazólio. Poecilanthe parviflora (coração-de-negro) é uma espécie arbórea brasileira utilizada na restauração florestal, para a qual não há testes estabelecidos para a determinação da viabilidade de suas sementes. Assim, a pesquisa objetivou adequar o método do teste de tetrazólio para a avaliação da viabilidade de sementes da referida espécie. A partir de estudos preliminares, relacionados à hidratação, ao preparo e à coloração das sementes, as sementes foram hidratadas pela imersão direta em água, até atingirem $30 \%$ e $40 \%$, e entre papel previamente umedecido com água, até atingirem $40 \%$. Após a hidratação, o tegumento das sementes foi retirado manualmente e os embriões foram imersos em solução $0,075 \%$ de tetrazólio por 90 minutos a $40^{\circ} \mathrm{C}$. Os resultados do teste de germinação foram empregados como referência para os de tetrazólio. É possível utilizar o teste de tetrazólio para avaliar a viabilidade das sementes de coração-de-negro. É recomendada a imersão das sementes em água, até atingirem $40 \%$, a remoção do tegumento e a coloração do embrião em solução $0,075 \%$ de tetrazólio, durante 90 minutos, no escuro, a $40^{\circ} \mathrm{C}$.
\end{abstract}

Termos para indexação: sementes florestais brasileiras, análise de sementes, germinação de sementes.

\author{
CORAÇÃO-DE-NEGRO (Poecilanthe parviflora BENTH. - FABACEAE-FABOIDEAE) SEEDS \\ VIABILITY EVALUATION BY THE TETRAZOLIUM TEST
}

\begin{abstract}
The increasing demand for Brazilian tree species seeds has been followed by the raise of the necessity to develop methods to evaluate seeds viability, mainly due to fast tests, as such as the tetrazolium. Poecilanthe parviflora (coração-de-negro) is a Brazilian tree species used in forest restoration. However, there is no established test to determine its seeds viability. So, the goal of this research was adequate the tetrazolium test to determine the seeds viability of this species. After preliminary studies, the seeds were pre-conditioned by their immersion in water, until they reach the moisture contents $30 \%$ and $40 \%$, and hydrated between papers previously soaked with water, until they reach the moisture content $40 \%$. After the pre-conditioning, seeds coats were removed manually and the embryos were immersed in $0,075 \%$ tetrazolium solution for 90 minutes, at $40^{\circ} \mathrm{C}$.
\end{abstract}

${ }^{1}$ Submetido em 06/01/2007. Aceito para publicação em 02/08/2007.

${ }^{2}$ Eng. Agrônomo, aluna de pós-graduação em Fitotecnia, USP/ESALQ: tais_leite@yahoo.com

${ }^{3}$ Eng. Agrônomo, aluno de pós-graduação em Fitotecnia, USP/ESALQ: pedrohsb@yahoo.com.br
${ }^{4}$ Prof. Doutor, USP/ESALQ -Departamento de Produção Vegetal: adlcnove@esal.usp.br

${ }^{5}$ Prof.Titular,USP/ESALQ-Departamento de Produção Vegetal: smcicero@ esalq.usp.br 
Tetrazolium test results were compared with the ones obtained in the germination test. The results indicated that the tetrazolium test can be used to evaluate $P$. parviflora seeds viability, mainly by the seeds immersion in water until they reach the moisture content $40 \%$ remove the seed coat and stain the embryo in $0,075 \%$ tetrazolium solution for 90 minutes at $40^{\circ} \mathrm{C}$.

Index terms: tree seeds, seed analysis, seeds germination.

\section{INTRODUÇ̃̃O}

A utilização de testes rápidos para avaliar a qualidade das sementes é importante, principalmente, para agilizar as decisões quanto ao manejo de lotes de sementes durante as etapas de pré e de pós-colheita. O teste de tetrazólio tem se mostrado como uma alternativa, pela qualidade e rapidez na determinação da viabilidade e do vigor das sementes, permitindo obter resultados, de modo geral, em menos de 24 horas (Barros, 1998).

É um teste que, pela observação da coloração obtida nas diferentes partes da semente, permite determinar a presença, a localização e a natureza das alterações nos tecidos das sementes (França Neto et al., 1999), além de, muitas vezes, possibilitar a identificação das causas da perda da viabilidade e do vigor.

A eficiência do teste em avaliar a viabilidade das sementes depende do desenvolvimento de método adaptado para cada espécie, de modo a definir as condições apropriadas para a hidratação, o preparo, a coloração e a avaliação das sementes.

No entanto, a utilização desse teste é restrita e a sua aplicação restringe-se, principalmente, às sementes de algumas espécies, tais como as de soja (França Neto et al.,1988, 1998, 1999), de milho (Dias e Barros, 1995), de gramíneas forrageiras (Carvalho e Toledo, 1976; Dias e Alves, 2001; Novembre et al., 2006) e de hortaliças feijão (Bhéring et al.,1996; Santos et al. 2007). Para as espécies florestais brasileiras, é utilizado de forma restrita, embora apresente potencial para ser empregado rotineiramente, uma vez que parte dessas espécies necessita de um período longo para as sementes germinarem.

Algumas pesquisas foram realizadas com o objetivo de desenvolver a técnica adequada para avaliação da viabilidade de sementes de espécies florestais brasileiras pelo teste de tetrazólio, como as desenvolvidas para as sementes de seringueira (Wetzel et al., 1992), de cedro, caroba, açoitacavalo e uva-do-japão (Amaral e Alcalay, 1997), de jenipapo (Nascimento e Carvalho, 1998), de teosinto (Maia et al., 1999), de sucupira-branca (Ferreira et al., 2001), de louro-pardo (Mendonça et al., 2001) e de canafístula (Oliveira et al., 2005).
A espécie Poecilanthe parviflora é da Floresta Estacional Semidecidual e da Floresta Estacional Decidual (Marchiori, 1997), sendo uma espécie clímax (Pinto, 1997), tem madeira dura e resistente ao apodrecimento e ao ataque de cupins, o que a torna indicada para a fabricação de móveis e para o uso na construção civil. É, também, recomendada para o uso em paisagismo, devido às características das folhas, e para a restauração florestal (Lorenzi, 2002).

O objetivo do presente trabalho foi adequar o método do teste de tetrazólio para a avaliação da viabilidade de sementes de coração-de-negro.

\section{MATERIAL E MÉTODOS}

A pesquisa foi desenvolvida no Laboratório de Sementes do Departamento de Produção Vegetal, da Escola Superior de Agricultura Luiz de Queiroz, da USP, com sementes de coração-de-negro (Poecilanthe parviflora Benth. - FafaceaeFaboideae). Foram utilizadas sementes colhidas em junho de 2004, na cidade de Assis-SP (lote 1), as quais foram armazenadas em câmara $\left(10^{\circ} \mathrm{C} \mathrm{e} 40 \%\right.$ de umidade relativa do ar) até a realização dos testes, e sementes colhidas em junho de 2006, na cidade de Piracicaba-SP (lote 2), utilizadas logo após a colheita.

Inicialmente, foram realizados testes preliminares relacionados à hidratação, ao preparo das sementes para a coloração na solução de tetrazólio e ao período de coloração. Foram testados seis métodos de hidratação (embebição entre papel toalha (EP) em germinador a $25^{\circ} \mathrm{C}$ e imersão direta em água (IA) até que as sementes atingissem 20, 30 e $40 \%$ de água), três métodos para o preparo inicial das sementes para a coloração na solução de tetrazólio (remoção do tegumento da semente, corte transversal da semente no sentido do comprimento e corte longitudinal da semente no sentido da espessura) e três tempos de coloração (60, 90 e 120 minutos).

O nível de hidratação das sementes estabelecido para o teste de tetrazólio foi definido com base em curvas de hidratação das sementes. Antes da obtenção das curvas, o teor de água inicial das sementes foi determinado pelo método de estufa a $105 \pm 3^{\circ} \mathrm{C}$ por 24 horas (Brasil, 1992). 
As curvas foram obtidas pelo monitoramento da massa úmida das sementes em hidratação, a cada oito horas, adotando-se como referência o teor de água inicial das sementes $(6,4 \%$ e $9,9 \%$, respectivamente, para os lotes 1 e 2), até que fosse observada a protrusão da raiz primária. $\mathrm{Na}$ hidratação entre papel, as sementes foram distribuídas entre duas folhas de papel-toalha umedecidas com a quantidade de água equivalente a 2,5 vezes a massa das folhas secas, sendo, em seguida, colocadas em caixas de plástico transparente $(11 \mathrm{~cm} \times 11 \mathrm{~cm} \times 3 \mathrm{~cm})$, em germinador a $25^{\circ} \mathrm{C}$. Na imersão em água, as sementes foram colocadas em $500 \mathrm{~mL}$ de água e mantidas no interior de germinador a $25^{\circ} \mathrm{C}$. As condições utilizadas para a hidratação das sementes para o teste de tetrazólio foram as mesmas descritas para a obtenção das curvas de hidratação.

Para o lote 2, antes da hidratação da semente foi cortado $0,5 \mathrm{~cm}$ da semente, no lado oposto ao do eixo, para a remoção do tegumento (Figura 1) que estava aderido ao embrião.

A partir dos resultados preliminares foram definidos os critérios para o preparo das sementes para o teste de tetrazólio considerando: eficiência de coloração dos cotilédones e do eixo embrionário (baseados na intensidade e na uniformidade da coloração), facilidade de remoção do tegumento e correlação dos valores obtidos nos testes de tetrazólio com

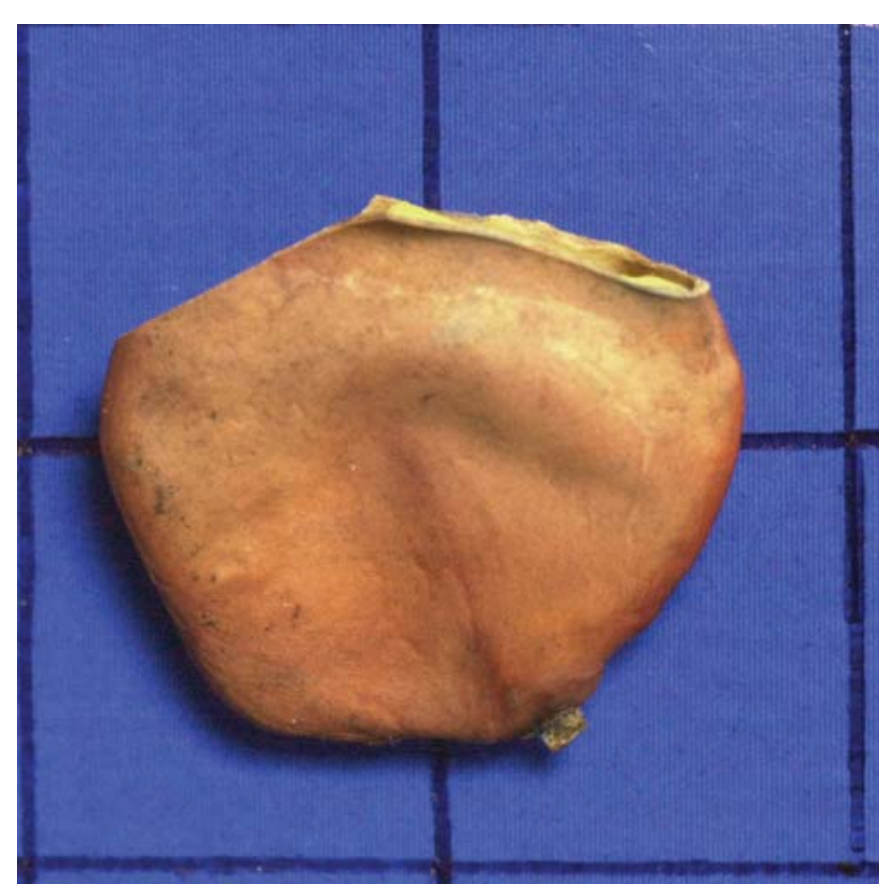

FIGURA 1. Semente de coração-de-negro com corte no lado oposto ao eixo antes de ser submetida à hidratação. os do teste de germinação. Com base nesses critérios e na aplicabilidade desses para ambos os lotes, foram, então, estabelecidas as condições para os experimentos seguintes.

As sementes foram hidratadas entre papel, até que atingissem $40 \%$ de água, e pela imersão direta em água, até que atingissem 30 e $40 \%$. A seguir, os tegumentos foram removidos das sementes e os embriões foram imersos para a coloração em solução $0,075 \%$ de $2,3,5$ trifenil cloreto de tetrazólio, durante 90 minutos, no escuro e a $40^{\circ} \mathrm{C}$. Após esse período, os embriões foram lavados em água corrente e mantidos em água até a avaliação.

Para a avaliação da viabilidade pelo teste de tetrazólio, os embriões foram seccionados longitudinalmente no sentido do comprimento. As duas metades foram, então, examinadas e, de acordo com a extensão e a intensidade dos tons avermelhados, a presença de áreas brancas leitosas e a localização dessas colorações em relação às áreas essenciais ao desenvolvimento, os embriões foram individualmente classificados em duas categorias: 1) viáveis e 2) não viáveis, de acordo com padrões indicados por Moore (1972).

Simultaneamente, foi realizado o teste de germinação, como forma de comparação dos resultados obtidos pelo teste de tetrazólio. Como não há informações sobre o teste de germinação para essa espécie (Brasil, 1992), foi utilizada a vermiculita como substrato e a temperatura de $25^{\circ} \mathrm{C}$, já que essas são as condições citadas como as mais favoráveis para a germinação das sementes da maioria das espécies arbóreas brasileiras (Piña-Rodrigues e Vieira,1988; Figliola et al., 1993; Brancalion et al., 2007).

A semeadura foi realizada em caixas plásticas transparentes $(11 \mathrm{~cm} \times 11 \mathrm{~cm} \times 3 \mathrm{~cm})$, entre vermiculita, a qual foi previamente esterilizada em estufa a $200^{\circ} \mathrm{C}$ por 2 horas. As sementes foram distribuídas sobre $30 \mathrm{~g}$ de vermiculita e, em seguida, cobertas com mais $20 \mathrm{~g}$ do mesmo substrato, constituindo uma camada de $0,5 \mathrm{~cm}$ de espessura sobre as sementes. Após a semeadura, o substrato foi umedecido até $70 \%$ de sua capacidade de retenção de água. As caixas plásticas foram mantidas em germinador a $25^{\circ} \mathrm{C}$, no escuro. Foram utilizadas oito repetições de 25 sementes por lote.

As sementes e as plântulas foram avaliadas de acordo com Brasil (1992), considerando-se como plântula normal as que apresentavam as estruturas essenciais do embrião desenvolvidas (Figura 2). A contagem final foi realizada após a estabilização da germinação, a qual ocorreu aos 20 dias.

Concomitantemente às avaliações, foram registradas imagens de plântulas normais, anormais, sementes mortas e dos embriões avaliados pelo teste de tetrazólio, por meio de câmera fotográfica digital Nikon, modelo D1. 

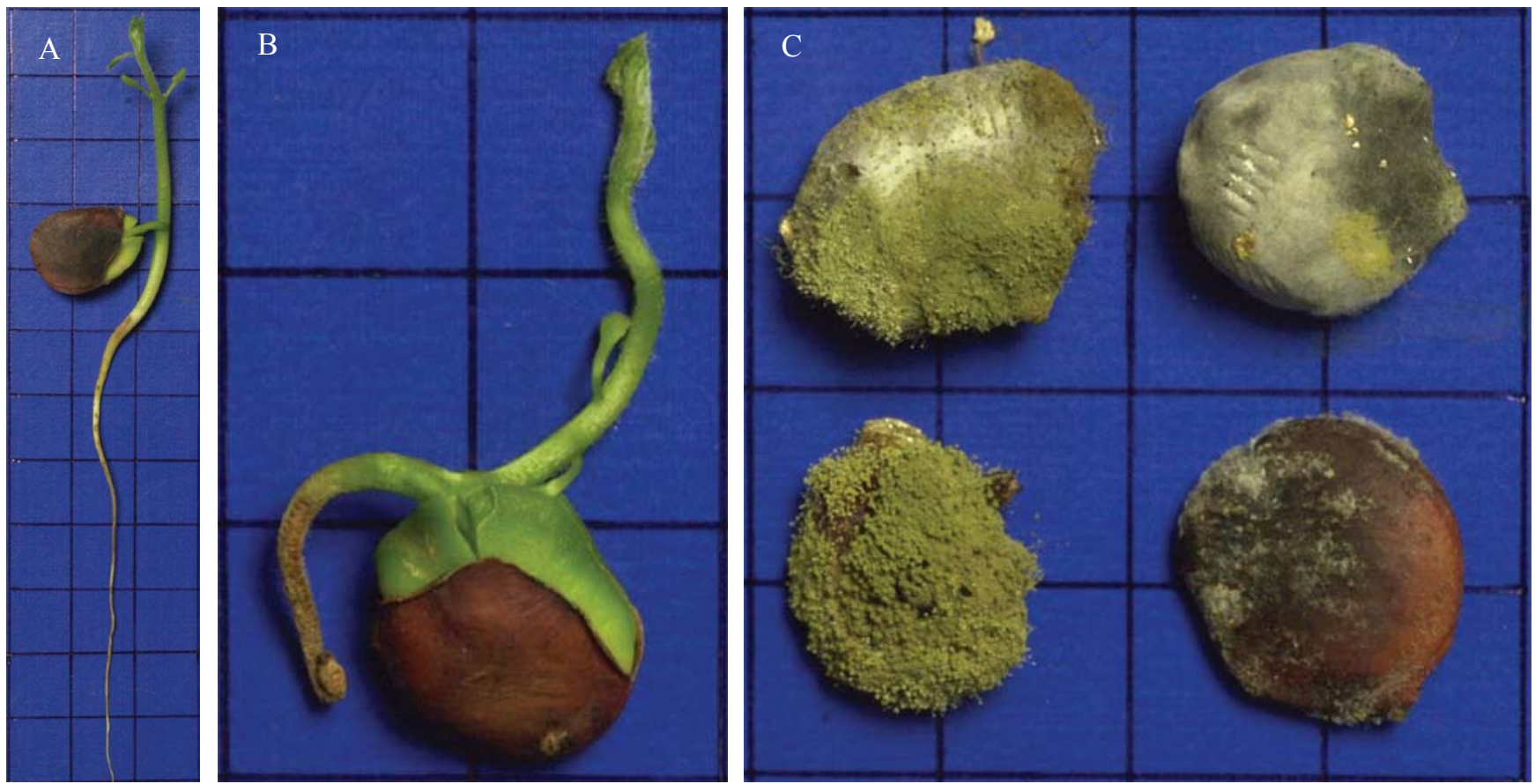

FIGURA 2. Plântula normal de coração-de-negro (a), plântula anormal (b) e sementes mortas (c).

Para verificar a estabilidade de resposta das sementes aos tratamentos, avaliação das sementes pelo testes de tetrazólio e de germinação, foram conduzidas duas épocas de análises, com um mês de intervalo.

O delineamento experimental utilizado foi o inteiramente casualizado, com oito repetições de 25 sementes por tratamento. Os dados obtidos nos testes de tetrazólio e de germinação foram transformados em arc sen da raiz quadrada de $\mathrm{x} / 100$ e submetidos à análise de variância. A comparação das médias foi feita pelo teste de Tukey (5\%) utilizando o programa SANEST (Zonta e Machado, 1984). Na tabela são apresentados os dados originais.

\section{RESULTADOS E DISCUSSÃO}

Os procedimentos gerais para a hidratação, o preparo e a coloração das sementes de coração-de-negro para o teste de tetrazólio foram definidos em testes preliminares (dados não apresentados). Todos os métodos de hidratação testados foram eficientes para as sementes do lote 1. Porém, para as sementes do lote 2, a remoção do tegumento (mesmo com a realização do corte na semente) após a hidratação em papel só foi possível para as sementes que tinham 40\% de água, enquanto que, na hidratação pela imersão direta em água, houve a possibilidade de remoção do tegumento tanto para as sementes com $30 \%$ de água como para as com $40 \%$.
A facilidade de remoção do tegumento das sementes do lote 1 em relação às do lote 2 pode ser explicada pelo período de armazenamento das sementes do lote 1 que, provavelmente, reduziu a aderência do tegumento ao embrião.

A coloração dos tecidos foi mais uniforme quando os embriões foram imersos em solução $0,075 \%$ de tetrazólio por 90 minutos a $40^{\circ} \mathrm{C}$, no escuro, quando comparado aos períodos de 60 e de 120 minutos. Estudos do teste de tetrazólio para as sementes de outras espécies vegetais indicaram também a possibilidade de redução do período de coloração das sementes, sem alterações significativas entre os resultados (Novembre et. al, 2007; Santos et al., 2007). Os tecidos vivos coloriram-se de róseo brilhante, os tecidos em processo de deterioração ou lesionados apresentavam-se vermelho carmim intenso, enquanto que os tecidos mortos apresentavam coloração branca leitosa.

Com base nas observações de intensidade de coloração, profundidade e localização das lesões foram estabelecidas duas classes de sementes: 1) viáveis e 2) não viáveis (Figuras 3 e 4). As alterações observadas nos tecidos das sementes foram provocadas pela absorção rápida de água e os danos naturais, evidenciados por tecidos necrosados.

Com relação à viabilidade das sementes (Tabela 1), para o lote 1, a hidratação das sementes entre papel (EP 40\%) causou redução significativa da viabilidade quando comparado aos demais tratamentos, representando o único tratamento não 

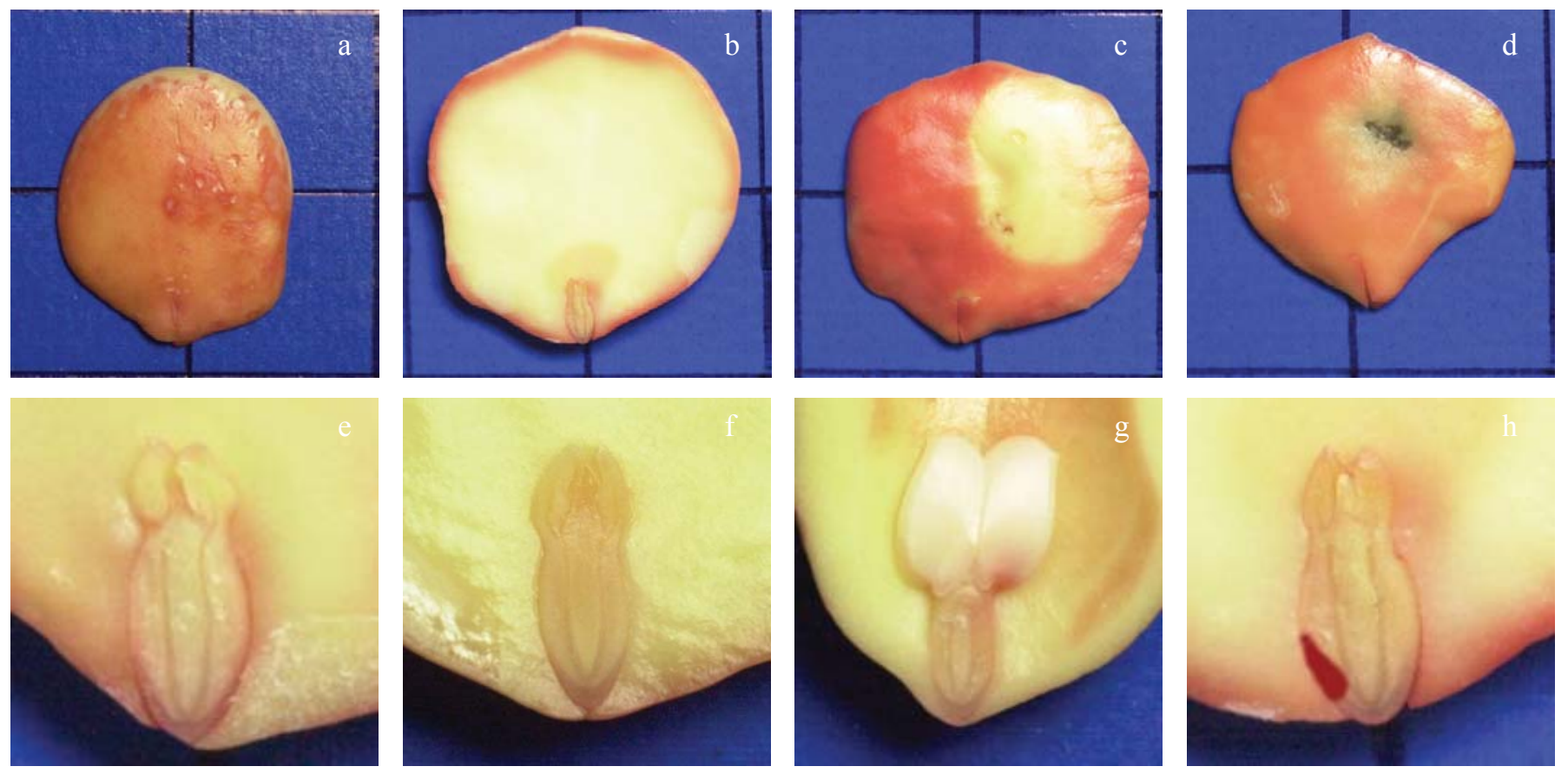

FIGURA 3. Semente viável: embrião com coloração rosa e tecidos com aspecto normal e firme (a, b, e, f); menos de $\mathbf{5 0 \%}$ dos cotilédones descoloridos (c) ou com regiões necrosadas (d), não afetando a região de ligação com o eixo embrionário; eixo embrionário (plúmula+eixo hipocótilo-radicula) com coloração vermelha intensa no córtex, porém, sem atingir o cilindro central (g e h).
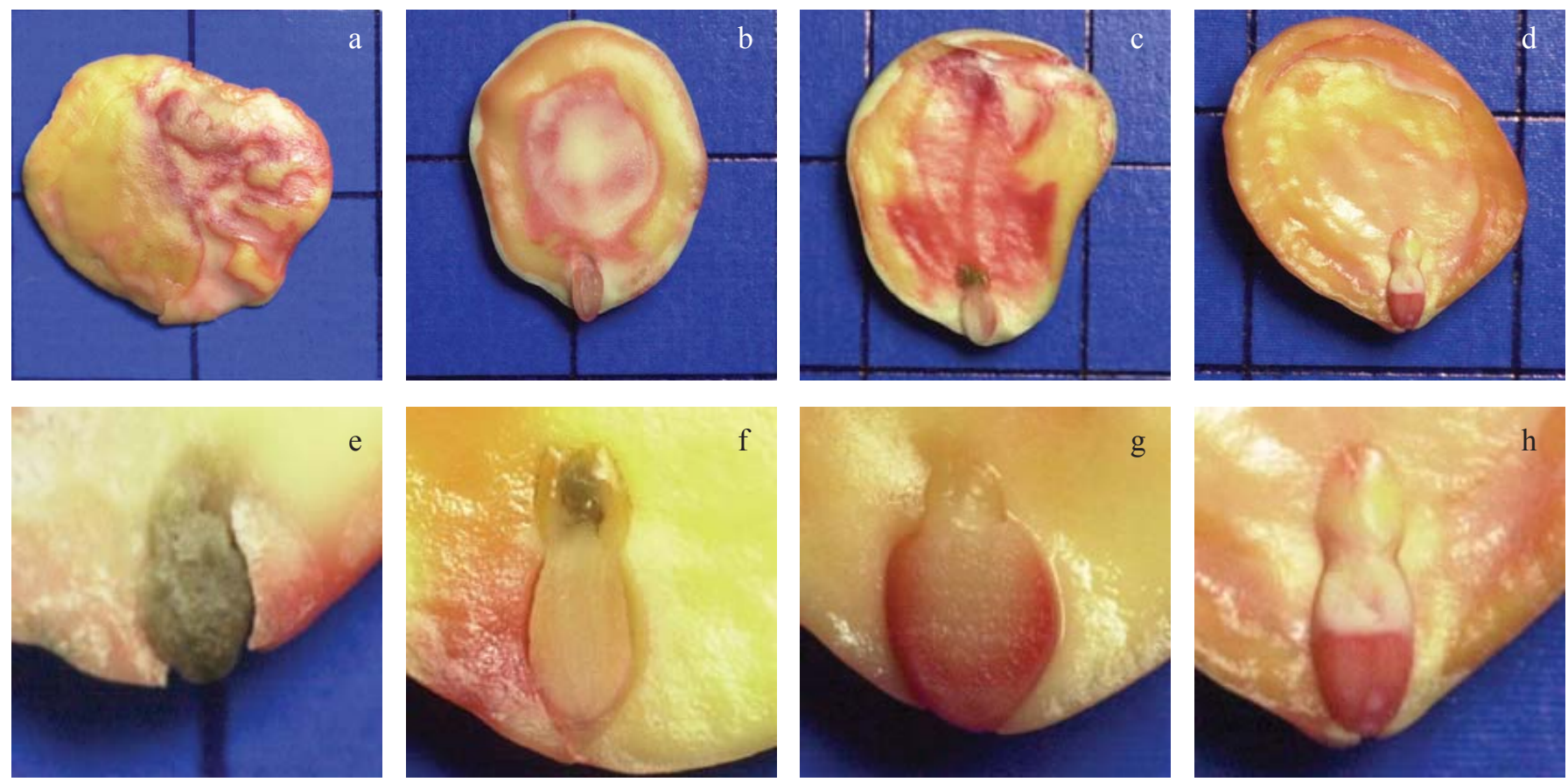

FIGURA 4. Semente não viável: mais de $50 \%$ dos cotilédones descoloridos, com coloração vermelha intensa (a, b, c, d) ou necrosados; eixo embrionário com regiões descoloridas, vermelha intensa e,ou, necrosados atingindo o cilindro central (e, f, g e h); 
recomendado. Para as sementes em que há a necessidade de remoção do tegumento como, por exemplo, as de abobrinha, Barros et al. (2005) verificaram que o método de imersão em água foi o mais eficiente para a remoção do tegumento das sementes e o que apresentou resultados similares aos obtidos no teste de germinação.

Para as sementes do lote 2 , não houve variação significativa entre os resultados do teste de tetrazólio e os de germinação (Tabela 1). Como a hidratação por imersão direta em água (IA 40\%) pode ser aplicada tanto para as sementes do lote 1 como para as do lote 2 , esse método foi considerado o mais adequado para a hidratação das sementes de coração-de-negro.

A menor porcentagem da germinação das sementes do lote 1 pode estar relacionada aos patógenos associados às sementes, principalmente, os fungos Aspergillus nigger, A. glaucus, A. ochraceus e Penicillium sp. (Figura 2c), geralmente associados ao armazenamento de sementes.

Outro fator a ser considerado na avaliação da viabilidade de sementes pelo teste de tetrazólio é o período de execução do teste. Mesmo sendo necessário retirar o tegumento das sementes, a avaliação da viabilidade pelo teste de tetrazólio, utilizando a imersão das sementes em água até que atinjam $40 \%$ de água, pode ser concluída em cinco horas e meia (três horas para a hidratação, 30 minutos para a remoção do tegumento, 90 minutos para a coloração e 30 minutos para a análise), enquanto que o período de tempo necessário para a conclusão do teste de germinação é de 20 dias. Assim, a possibilidade de avaliação da viabilidade das sementes de coração-de-negro em até um dia permite que algumas decisões relacionadas à produção, colheita, análise e comercialização

TABELA 1. Porcentagens de sementes viáveis de coraçãode-negro obtidas pelos testes de tetrazólio sementes hidratadas entre papel e com $40 \%$ de água (EP 40\%) e por imersão direta em água e com $30 \%$ e $40 \%$ de água (IA 30\% e IA 40\%), e de germinação (G).

\begin{tabular}{clc}
\hline Tratamentos & Lote 1 & Lote 2 \\
\hline EP $40 \%$ & $64 \mathrm{a}$ & $68 \mathrm{a}$ \\
IA $30 \%$ & $56 \mathrm{ab}$ & $59 \mathrm{~b}$ \\
IA $40 \%$ & $58 \mathrm{ab}$ & $66 \mathrm{ab}$ \\
$\mathrm{G}$ & $52 \mathrm{~b}$ & $66 \mathrm{ab}$ \\
\hline $\mathrm{CV}(\%)$ & 11,76 & 8,61 \\
\hline
\end{tabular}

Médias seguidas da mesma letra, nas colunas, não diferem entre si pelo teste de Tukey, a $5 \%$. dessas sementes possam ser agilizadas e ao mesmo tempo constituir parâmetro de avaliação da qualidade das sementes. Nesse sentido, Barton (1985) e França Neto et al. (1998) mencionaram que em função da rapidez de realização do teste de tetrazólio, é possível prevenir a comercialização de lotes de baixa qualidade fisiológica.

\section{CONCLUSÕES}

É possível utilizar o teste de tetrazólio para avaliar a viabilidade das sementes de coração-de-negro. É recomendada a imersão das sementes em água, até atingirem $40 \%$ de água, a remoção do tegumento e a coloração do embrião em solução $0,075 \%$ de tetrazólio, durante 90 minutos, no escuro, a $40^{\circ} \mathrm{C}$.

\section{REFERÊNCIAS}

AMARAL, D.M.I.; ALCALAY, N. Emprego do teste de tetrazólio em cinco espécies florestais do Rio Grande do Sul. Informativo ABRATES, Curitiba, v.7, n.1/2, p.221, 1997.

BARROS, A.C.S. Testes para avaliação rápida da viabilidade e do vigor de sementes de soja. Piracicaba: ESALQ, 1988. (Dissertação - Mestrado).

BARROS, D. I.; DIAS, D. C. F. S.; BHERING, M.C. Uso do teste de tetrazólio para avaliação da qualidade de sementes de abobrinha. Revista Brasileira de Sementes, Brasília, vol.27, n..2, p.165-171, 2005.

BARTON, L.V. Methods of testing for viability. In: BARTON, L.V. Seed preservation and longevity. New Dehli: IBS, 1985. p.121-137.

BHÉRING, M.C.; SILVA, R.F.; ALVARENGA, E.M.; DIAS, D.C.F.S.; PENA, M.F. Avaliação da viabilidade e do vigor de sementes de feijão-de-vagem (Phaseolus vulgaris $\mathbf{L}$.) pelo teste de tetrazólio. Viçosa: Universidade Federal de Viçosa, 1996. 27p.

BRANCALION， P.H.S.; NOVEMBRE， A.D.L.C.; RODRIGUES, R.R.; CHAMMA, H.M.C.P. Estabelecimento da temperatura ótima para a germinação das sementes de 272 espécies arbóreas nativas do Brasil. Informativo ABRATES, Brasília, v.17, n. 1,2,3, p.55-68, 2007.

BRASIL, Ministério da Agricultura e Reforma Agrária. Regras para análise de sementes. Brasília: SNDA/DNDV/ CLAV, 1992. 365p.

CARVALHO, N.M.; TOLEDO, F.F. Determinação da germinação de sementes de capim colonião (Panicum maximum Jacq) através do uso do tetrazólio. I - Proposição de um método de trabalho. Científica, Jaboticabal, v.4, n.2, p.185-190, 1976. 
DAVIDE, A.C.; MALAVASI, M.M.; OLIVEIRA, L.M.; MACHADO, C.F.; TONETTI, O.A.O. Uso do teste de tetrazólio para avaliar a qualidade de sementes de pau-santo (Kielmeyera coriacea (Spr.) Mart.) - Guttiferae. Informativo ABRATES, Curitiba, v.7, n.1/2, p.219, 1997.

DIAS, M.C.L.L.; ALVES, S.J. Avaliação da viabilidade de sementes de Brachiaria brizantha (Hoscst. Ex A. Rich) Stapf pelo teste de tetrazólio. Informativo ABRATES, Londrina, v.11, n.2, p.317, 2001.

DIAS, M.C.L.L.; BARROS, A.S.R. Avaliação da qualidade de sementes de milho. Londrina: IAPAR, 1995. 43p. (Circular, 88).

FERREIRA, R.A.; DAVIDE, A.C.; MOTTA, M.S. Vigor e viabilidade de sementes de Senna multijuga (Rich.) Irwin Vigor e viabilidade de sementes de Senna multijuga (Rich.) Irwin et Barn. e Senna macranthera (Collad.) Irwin et Barn.; num banco de sementes em solo de viveiro. Revista Brasileira de Sementes, Brasília, v.26, n.1, p.24-31, 2004.

FERREIRA, R.A.; GUIMARÃES, M.G.G.C.; PINHO, E.V.R.; TONETTI, O.A.O. Morfologia de sementes e plântulas e avaliação da viabilidade da semente de sucupirabranca (Pterodon pubescens Benth. Fabaceae) pelo teste de tetrazólio. Revista Brasileira de Sementes, Brasília, v.23, n.1, p. 108-115, 2001.

FIGLIOLIA, M.B.; OLIVEIRA, E.C.; PIÑARODRIGUES, F.C.M. Análise de sementes. In: AGUIAR, I.B.; PIÑARODRIGUES, F.C.M.; FIGLIOLIA, M.B.(Coord.). Sementes florestais tropicais. Brasília: ABRATES, 1993, p.137-174.

FRANÇA NETO, J.B.; KRZYZANOWSKI, F.C.; COSTA, N.P. Metodologia do teste de tetrazólio em sementes de soja. In: KRZYZANOWSKI, F.C.; VIEIRA, R.D.; FRANÇA NETO, J.B. (eds). Vigor de sementes: conceitos e testes. Londrina: ABRATES. 1999. p.8.5-1 - 8.5-28.

FRANÇA NETO, J.B.; KRZYZANOWSKI, F.C.; COSTA, N.P. $O$ teste de tetrazólio em sementes de soja. Londrina: EMBRAPA-CNPSo, 1998. 72p. (EMBRAPA-CNPSo. Documentos, 116).

FRANÇA NETO, J.B.; PEREIRA, L.A.G.; COSTA, N.P.; KRZYZANOWSKI, F.C.; HENNING, A.A. Metodologia do teste de tetrazólio em sementes de soja. Londrina: EMBRAPA- CNPSo, 1988. 60p. (Série Documento, 32).

LORENZI, H. Árvores brasileiras: manual de identificação e cultivo de plantas arbóreas do Brasil. 4ª ed. Nova Odessa: Instituto Plantarum, 2002. v.1. 368p.

MAIA, M.S.; RODRIGUES, A.P.D.C.; GUIMARÃES, I.F. Determinação da metodologia para o teste de tetrazólio em sementes de teosinto (Euchlaena mexicana Schrader). Informativo ABRATES, Curitiba, v.9, n.1/2, p.210, 1999.

MARCHIORI, J.N.C. Dendrologia das angiospermas: leguminosas. Santa Maria: Ed. da Universidade Federal de Santa Maria, 1997. 200p.

MENDONÇA,E.A.F.;RAMOS,N.P.;PAULA,R.C.Viabilidade de sementes de Cordia trichotoma (Vellozo) arrabida ex Steudel (Louro Pardo) pelo teste de tetrazólio. Revista Brasileira de Sementes, Brasília, vol. 23, n. 2, p.64-71, 2001.

MOORE, R.P. Interpretation of color differences in tetrazolium testing. Seed Technologist News, Zürich, [S.1.], v. 44, n. 3, p. 22-24, 1972.

NASCIMENTO,W.M.O.;CARVALHO,N.M.Determinação da viabilidade de sementes de jenipapo (Genipa americana L.) através do teste de tetrazólio. Revista Brasileira de Sementes, Brasília, v.20, n.2, p.470-474, 1998.

NOVEMBRE, A.D.L.C.; CHAMMA, H.M.C.P.; GOMES, R.B.R. Viabilidade das sementes de braquiária pelo teste de tetrazólio. Revista Brasileira de Sementes, Brasília, v.28, p.147-151, 2006.

OLIVEIRA, L.M.; CARVALHO, M.L.M.; DAVIDE, A.C. Teste de tetrazólio para avaliação da qualidade de sementes de Peltophorum dubium (Sprengel) Taubert leguminosae caesalpinioideae. Cerne, Lavras, v. 11, n. 2, p. 159-166, abr./ jun. 2005.

PIÑA-RODRIGUES, F.C.M.; VIEIRA, J.D. Teste de germinação. In: PIÑA RODRIGUES, F.C.M. Manual de Análise de Sementes Florestais. Campinas: Fundação Cargill, 1988, 100p.

PINTO, J.R.R. Levantamento florístico, estrutura da comunidade arbóreo-arbustiva e suas correlações com variáveis ambientais em uma floresta de vale no Parque Nacional da Chapada dos Guimarães, Mato Grosso. Lavras: Universidade Federal de Lavras, 1997. 85p. (Dissertação - Mestrado).

SANTOS, M.A.O.; NOVEMBRE, A.D.L.C.; MARCOS FILHO, J. Tetrazolium test to assess viability and vigour of tomato seeds. Seed Science and Technology, Zürich, v. 35, p. 213-223, 2007.

WETZEL, M.M.V.S.; CICERO, S.M.; FERREIRA, B.C.S. Aplicação do teste de tetrazólio em sementes de seringueira. Revista Brasileira de Sementes, Brasília, v.14, n.1, p.83-88, 1992.

ZONTA, E.P.; MACHADO, A.A. Sistema de análise estatística para microcomputadores-SANEST. Pelotas, 1984. 109p. 